\title{
A qualidade da prescrição de antimicrobianos em ambulatórios públicos da Secretaria Municipal de Saúde de Belo H orizonte, MG
}

\author{
The quality of antibiotics prescription in public health services \\ of Belo H orizonte, M G
}

\author{
Patrícia de $M$ agalhães $A$ brantes ${ }^{1}$ \\ Sérgia M aria Starling M agal hães ${ }^{2}$ \\ Francisco deAssisAcúrcio ${ }^{2}$ \\ Emília Sakurai $^{3}$
}

${ }^{1}$ Farmácia Distrital CentroSul, Secretaria M unicipal de Saúde de Belo H orizonte. Rua Pernambuco 237 Funcionários. 30130-150 Belo H orizonte M G patricma@pbh.gov.br

${ }^{2}$ FaculdadedeFarmácia UniversidadeFederal de M inas Gerais.

Instituto deCiências Exatas, Universidade Federal de M inas Gerais.
Abstract This study investigates the use of antibiotics and prescribing patterns and identifies the antibiotics most frequently prescribed in public health units of Belo H orizonte, M G. The methods used were observational, cross-sectional study aimed at analyzing the consistency between a sample of medical records and antibiotic prescriptions dispensed during March 2002 in eleven public health units in Belo Horizonte, M inas Gerais, Brazil. Pediatrics showed the highest proportion of antibiotic prescribing among four specialties; amoxicillin was the most frequently prescribed antibiotic, followed by benzathine penicillin $G$, sulfamethoxazole/trimethoprim, and erythromycin. U pper respiratory tract infections, tonsillitis, acuteotitis media and urinary tract infectionswere the diagnostic hypotheses most frequently recorded. O verall consistency between the recorded diagnostic hypotheses and the prescribed antibiotic was lower than $75 \%$. The duration of the therapy prescribed varied largely and in approximately $10 \%$ of the prescriptions this information was lacking. M oreover, data on the patient such as age, body weight, co-morbidity, diagnostic hypotheses and adverse reactions, were systematically absent in the medical records. This study demonstrates the need for interventions in order to promote a more rational use of antibiotics.

Key words Antibiotic, Primary care, Protocols, Prescribing
Resumo Este estudo investiga o uso de antimicrobianos e os padrões de prescrição e identifica os antimicrobianos mais freqüentemente prescritos nas unidades do serviço público de saúde de Belo H orizonte, M G. 0 estudo foi observacional, transversal de investigação da utilização da prescrição de antibacterianos em unidades públicas de saúde de Belo Horizonte, a partir da avaliação de amostra de prontuários e prescrições dispensadas no mês de março de 2002. A pediatria apresentou o maior índice de prescrição de antimicrobianos. A amoxicilina foi 0 antibacteriano mais prescrito. As hipóteses diagnósticas registradas com maior freqüência foram infecções das vias aéreas superiores, tonsilite e otite média. 0 percentual de inadequação entre hipótese diagnóstica registrada e antimicrobiano prescrito foi superior a $25 \%$. O bservou-se variabilidade nos tempos de tratamento instituídos e, em cerca de $10 \%$ das prescrições, o dado estava ausente. Verificou-se uma ausência sistemática de registro de informações gerais no prontuário. 0 estudo demonstrou a necessidade de intervenções queassegurarem o cumprimento dos protocolos como forma de garantir o uso adequado dos antimicrobianos.

Palavras-chave Antimicrobianos, Atenção primária, Protocolos, Prescrição 


\section{Introdução}

As doen ças infecciosas são responsáveis por grande parte das morbidades que motivam consultas médicas, particularmentena infância ${ }^{1,2,3}$. Em vista disso, os antimicrobianos constituem uma classe de medicamentos amplamente utilizados em atenção primária, ocupando sempre um dos primeiros lugares entreas classes de medicamentos mais utilizadas ${ }^{4,5}$.

A utilização de antimicrobianos tem merecido destaque nas políticas de racionalização do uso de medicamentos pelo fato de os antimicrobianos encontrarem-se entre os medicamentos mais consumidos em atenção primária e por serem, na prática médica, os fármacos que mais se empregam de forma errônea e abusiva. Existem evidências deque o uso inapropriado do antimicrobiano ocorre em aproximadamente $50 \%$ dos casos e está freqüentemente associado a infecções das vias aéreas superiores (IVAS) ${ }^{6,7}$. Esse uso inadequado traz como grave conseqüência a seleção e disseminação de microorganismos resistentes, despertando a necessidade do emprego de medicamentos mais novos, quase sempre de espectro mais amplo e de maior custo. Além do problema relativo ao desenvolvimento de resistência microbiana esuas conseqüências médicas, estepadrão deutilização tem conseqüências ecológicas e econômicas substanciais, pois agrava 0 custo social e pessoal das doenças bacterianas ${ }^{6}$.

Pode-se ponderar, ainda, que a prática da automedicação e o acesso não controlado a medicamentos são fatores que agravam o quadro geral de uso de medicamentos, particularmente dos antimicrobianos $s^{6,8}$.

0 uso inadequado de antimicrobianos pode ser classificado em quatro categorias distintas, sendo a primeira referente aos aspectos de diagnóstico, ou seja, à caracterização de um quadro infeccioso passível de tratamento. Em uma segunda categoria, destaca-se a seleção do antimicrobiano adequado, considerando sua indicação, espectro de ação e propriedades farmacocinéticas. A terceira se refere à duração do tratamento ea última engloba os aspectos posológicos como dose, intervalo entre doses e via de administração ${ }^{9}$. Os erros de prescrição envolvendo os aspectos posológicos e duração de tratamento têm sido objeto de vários estudos. Lesar ${ }^{10}$ relatou, em estudo realizado em um hospital-escola americano, que a maioria dos erros de dose mais comuns $(53,5 \%)$ envolvia os antimicrobianos. Vergeles-Blanca et al. ${ }^{4}$, em seu estudo realizado em um serviço de urgência hospitalar na Espa- nha, observaram que a posologia inadequada foi responsável por $47,4 \%$ dos erros de prescrição. Fijn et al. ${ }^{9}$ observaram que a inadequação dos dados posológicos e do tempo de tratamento é fator freqüentementeassociado à não-adesão aos protocolos deanti bacterianos preconizados para uso no meio hospitalar.

A adoção de guidelines e protocolos clínicos para o uso de antimicrobianos permite uma redução nas decisões individuais e a uniformização das condutas, priorizando aquelas de maior sustentação clínica ${ }^{2,11}$, propiciando às auditorias médicas um instrumento útil para a verificação da adesão aos protocolos propostos, permitindo a detecção de desvios nas condutas preconizadas e a real ização de intervenções que minimizem os erros de prescrição.

Em Belo Horizonte, os gastos com medicamentos, inclusivecom antimicrobianos, vêm aumentando gradativamentenos últimos anos. Em $2002,15,5 \%$ do orçamento para medicamentos da Assistência Farmacêutica Básica foram consumidos por esta classe terapêutica.

Considerando o impacto do uso inadequado de antimicrobianos na saúde pública e a importância de conhecer as implicações da utilização destes medicamentos na comunidade, este estudo tem como objetivo avaliar a prescrição de antibacterianos em Unidades Básicas do Serviço Público de Saúde(UBS) da Região Centro-Sul de Belo Horizonte, sob a administração da Gerência de Saúde Centro-Sul (GERSA-CS), nos aspectos referentes à seleção do antimicrobiano e ao esquema terapêutico adotado (dose, intervalo entre doses e duração do tratamento).

\section{Material emétodos}

O município de Belo Horizonte tem população de 2.229.697 habitantes e ocupa uma área de $330,23 \mathrm{~km}^{2}$, dividida em noveregiões político-administrativas. Em cada administração regional, existeuma gerência de saúde (GERSA) queadministra os serviços de saúde do seu território ${ }^{12}$.

A Regional Centro-Sul éconstituída por uma população de 265.743 habitantes, representando $11,92 \%$ da população do município, eagrega em torno de $14 \%$ dos domicílios particulares permanentes deBelo H orizonte. A Regional concentra ainda cerca de $20 \%$ das vilas e favelas do município, correspondendo a $18 \%$ da população neste tipo de residência ${ }^{12}$.

Foi realizado um estudo descritivo, transversal, com base no levantamento das receitas mé- 
dicas de anti bacterianos de uso sistêmico dispensadas no mês de março de 2002, em unidades de atenção primária da Gerência de Saúde CentroSul da Secretaria Municipal de Saúde de Belo H orizonte (SM SA/BH), e de seus respectivos prontuários médicos.

Durante o mês de março de 2002, foram aviadas 4.088 receitas contendo pelo menos um antimicrobiano de uso sistêmico, classificado, segundo a Anatomical Therapeutic Chemical (ATC), nos grupos $\int 01$ (antibacterianos para uso sistêmico) e G04 (antissépticos urinários, antiinfecciosos) ${ }^{13}$ nas unidades de saúde do estudo. Das 4.088 receitas examinadas, 2.202 foram geradas nas unidades municipais de saúde e o restante, em outros serviços públicos e particulares, não tendo se constituído objeto deste estudo. 0 tamanho da amostra foi determinado estimandose uma proporção de $50 \%$ de receitas completas relativas a cada item da pesquisa, com nível de confiança de $95 \%$, erro máximo de $1 \%$ emargem de perdas de $20 \%$. Uma amostra inicial de 814 receitas foi obtida para o estudo das prescrições.

Para a avaliação dos prontuários, selecionousedeste conjunto uma nova amostra de 187 receitas, estratificada e proporcional ao número de receitas originadas em cada unidade de saúde pesquisada. Determinou-se o tamanho da amostra, considerando-se $50 \%$ dereceitas com $50 \%$ deinadequação da prescrição, 95\% de grau de confiança e erro máximo de 5\%, com correção para população finita. Procedeu-se à busca dos prontuários a partir das receitas amostradas e, quando este não era encontrado, era substituído pelo primeiro imediatamente posterior ao sorteado e, se novamente o prontuário não fosse encontrado, era substituído pelo posterior seguinte, e assim sucessivamente. Prontuários completamenteilegíveis, deforma impedir o registro deinformações mínimas necessárias, foram substituídos conforme o procedimento descrito anteriormente.

Os seguintes aspectos foram investigados: especialidade do prescritor; sexo, data de nascimento, idade e peso do paciente; hipótese diagnóstica registrada (HD); técnicas diagnósticas utilizadas; relato de co-morbidades; utilização de antimicrobianos nos três meses anteriores e nos três meses posteriores à consulta que gerou a receita. Para cada antibacteriano, buscou-se a apresentação, dose, intervalo entre doses, duração do tratamento, assim como a adequação de cada item, de acordo com as recomendações descritas em guias de utilização de antimicrobianos de especialistas esociedades reconhecidas ${ }^{14,15,16}$. 0 processamento e a análise dos dados foram realiza- dos utilizando o software EPIINFO versão 2000. Para a análise dos dados, procedeu-se à distribuição de freqüência das variáveis estudadas, organizadas em tabelas e gráficos.

\section{Resultados}

As informações dos prontuários foram agrupadas quanto a aspectos referentes ao paciente, ao prescritor e ao antimicrobiano prescrito. $\mathrm{Na} \mathrm{Ta-}$ bela 1, estão apresentados os percentuais de presença de informações nos prontuários. Verificouse que a data de nascimento esteve presente em um percentual baixo dos prontuários. A ausência da HD em mais de $30 \%$ dos prontuários impediu que se avaliasse a adequação do antibacteriano selecionado, assim como de sua dosagem.

Dentreos pacientes pediátricos, 53,8\% tinham entre um equatro anos. Para esse grupo, o registro do peso estava ausente em cerca de $40 \%$ dos prontuários. Encontrou-se registro de co-morbidades em apenas quatro prontuários, sendo um caso de diabetes mellitus etrês de hipertensão arterial. Esta freqüência sugere um baixo índice de registro dessa informação.

Foi efetuada a busca do registro, nos prontuários, do uso de antimicrobianos nos seis meses em torno da consulta (três meses anteriores etrês posteriores) e dos respectivos diagnósticos registrados. Dos prontuários com registro de mais de um tratamento antimicrobiano no período, 17,6\% utilizaram dois tratamentos, 4,8\% usaram três ciclos de tratamento e $0,5 \%$ usou quatro. A HD foi a mesma que originou a consulta em março de 2002, em 8,6\% dos casos de utilização de mais deum ciclo de antimicrobiano.

Tabela 1. Percentual de presença de informações nos prontuário.

\begin{tabular}{lc}
\hline \multicolumn{1}{c}{ Variável } & Presença (\%) \\
\hline Data de nascimento & 36,4 \\
Identificação da idade & 89,3 \\
Crianças até 12 anos & 59,9 \\
Adultos 20-40 anos & 30,7 \\
Gênero feminino & 57,2 \\
Registro de peso na pediatria & 59,8 \\
Registro de co-morbidades & 2,1 \\
Registro de mais de um & 23,0 \\
tratamento com antimicrobianos & \\
Registro da Hipótese diagnóstica & 69,5 \\
\hline
\end{tabular}

Fonte: Secretaria M unicipal deSaúde de Belo H orizonte, 2002. 
As HD registradas com maior freqüência foram tonsilite $(19,2 \%)$, otite média ( $13,8 \%)$, infecção do trato urinário (ITU) (13,8\%) eimpetigo $(10,8 \%)$. AsH D envolvendo infecções do trato respiratório, incluindo a tonsilite, foram responsáveis por $43,1 \%$ das prescrições de antimicrobianos (Tabela 2).

0 número distinto de antimicrobianos prescritos foi de dez. Na SM SA/BH, em 2002, estavam padronizados onze antibacterianos de uso sistêmico em dezessete apresentações. Os antimicrobianos mais prescritos foram a amoxicilina, a benzilpenicilina benzatina, o sulfametoxazol + trimetoprim e a eritromicina (Gráfico 1).

Observa-se na Tabela 2 que, do total de HD registradas nos prontuários, a maioria $(75,4 \%)$ foi baseada em exame clínico, queixas, sinais e sintomas. Os exames laboratoriais se concentraram basicamente na infecção do trato urinário e contribuíram para o diagnóstico de al guns casos de pneumonia, sinusitee IVAS.

No Gráfico 2, são apresentados os percentuais de adequação para as variáveis relativas a antimicrobiano selecionado para a HD registrada, dose, intervalo entre doses e duração. Foram eliminados os prontuários com dados ilegíveis e aqueles nos quais as informações para avaliação de adequação não estavam disponíveis. 0 item que apresentou melhor resultado em relação à adequação foi a dose para adulto e o que apresentou resultado menos satisfatório foi a indicação de antimicrobiano para HD registrada em adulto, com cerca de $73 \%$ de adequação.

A adequação da dose prescrita não pôde ser obtida em dezesseis prontuários de adulto (8,6\%) por falta da apresentação dos medicamentos. Contudo, nos prontuários nos quais se pôde obter esta informação, a dose prescrita teveíndice de adequação de $100 \%$.

$\mathrm{Na}$ pediatria, houve um alto índice de perda da informação de adequação de dose devido à ausência de registro do peso da criança (35), por falta da apresentação do medicamento (23) e devido à ilegibilidade (1), totalizando 48 perdas $(42,8 \%)$. No restante da amostra em que as informações estavam acessíveis, a adequação da dosefoi de $95,4 \%$, observando-sena pediatria uma freqüência maior de erros com relação à dose, quando comparado à prescrição para adultos.

Os dados apresentados na Tabela 3 mostram que a eritromicina e o cotrimoxazol (sulfametoxazol + trimetoprim) concentraram os resultados menos satisfatórios de adequação. Os meIhores resultados foram observados para a amo-

Tabela 2. Hipótese diagnóstica, antimicrobiano prescrito e método diagnóstico relatado nos prontuários selecionados.

\begin{tabular}{lcccccc}
\hline \multirow{2}{*}{ Hipótese diagnóstica } & \multicolumn{2}{c}{ Total } & & \multicolumn{3}{c}{ Método diagnóstico relatado } \\
\cline { 2 - 3 } \cline { 5 - 6 } & $\mathrm{n}$ & $\%$ & & Exame clínico (\%) & Exame clínico + testes laboratoriais (\%) \\
\hline Tonsilite & 25 & 13,4 & & 96,0 & - \\
O M A & 18 & 9,6 & & 83,3 & - \\
ITU & 18 & 9,6 & & 5,5 & 88,9 \\
Impetigo & 14 & 7,5 & & 85,7 & - \\
DPOC/ asma/Bronquite & 11 & 5,9 & & 90,9 & 9,1 \\
IVAS & 10 & 5,3 & & 80,0 & 20,0 \\
Infecções associadas & 10 & 5,3 & & 90,0 & - \\
rinossinusite & 9 & 4,8 & & 77,8 & 11,1 \\
Feridas infectadas & 9 & 4,8 & & 100,0 & - \\
Celulite & 3 & 1,6 & & 100,0 & - \\
Pneumonia & 1 & 0,6 & & - & 100,0 \\
Outras & 2 & 1,1 & & - & 50,0 \\
Ausência de informação* & 57 & 30,5 & & & \\
Total & 187 & 100,0 & & &
\end{tabular}

Fonte: Secretaria M unicipal de Saúde de Belo H orizonte, 2002.

OM A- O titemedia aguda; DPOC - D oença pulmonar obstrutiva crônica; ITU - Infecção do trato urinário; IVAS- Infecções das vias aéreas superiores

*Ausência do registro de qualquer hipótese diagnóstica 
Gráfico 1. Adequação de dose, intervalo entre doses, duração do tratamento e indicação, de acordo com a hipótese diagnóstica registrada, Belo Horizonte, 2002.

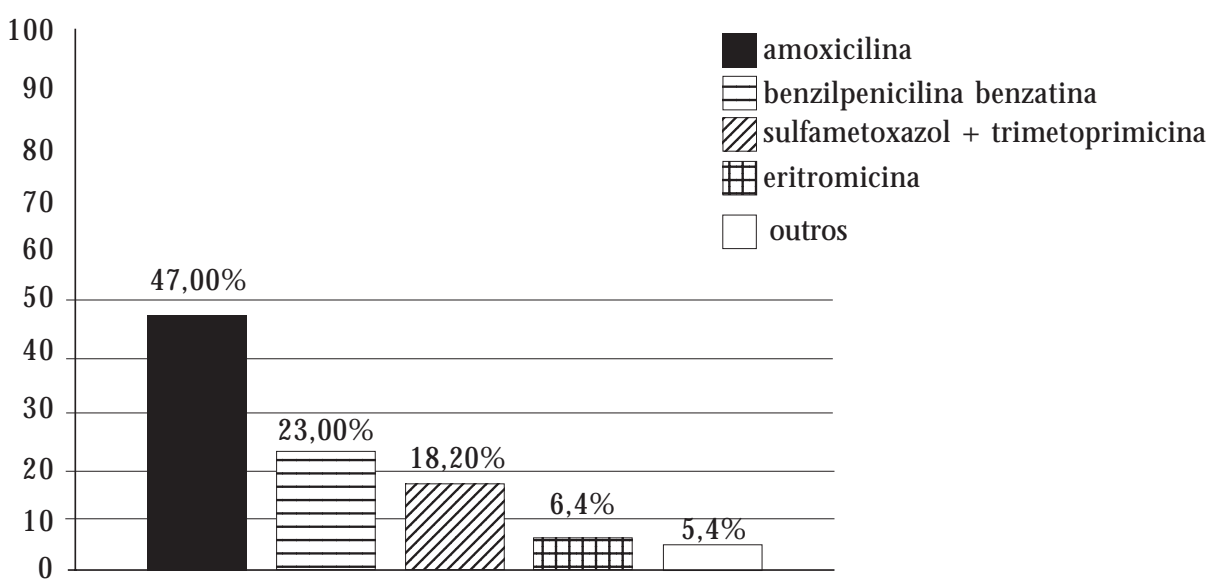

Gráfico 2. Adequação de dose, intervalo entre doses, duração do tratamento e indicação, de acordo com a hipótese diagnóstica registrada, Belo Horizonte, 2002.

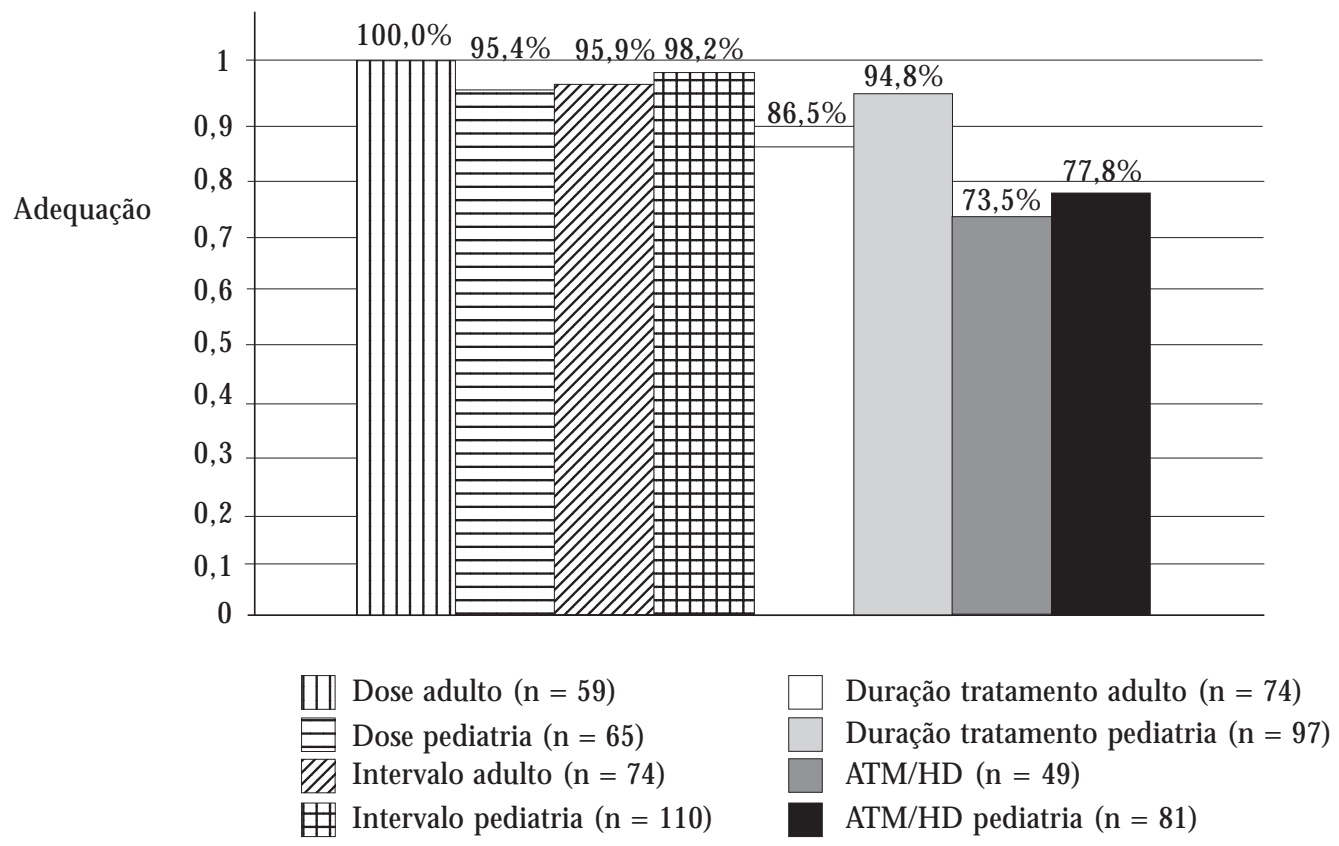

xicilina e benzilpenicilina benzatina, sendo a freqüência de adequação superior a $87,0 \%$ para as variáveis dose, intervalo e duração do tratamento. O bservam-se baixos percentuais de adequação da indicação, de acordo com a HD, para a benzilpeni- cilina benzatina e de duração do tratamento para a eritromicina, ambos para uso em adultos. A duração do tratamento, essencial para a terapia com antimicrobiano, estava ilegível em um prontuário e ausente em quinze. 
Em 82\% dos prontuários, foi prescrito pelo menos mais um medicamento junto com o antimicrobiano, totalizando 249 medicamentos. Em $37,3 \%$ dessas receitas, foi prescrito mais um medicamento, em $50,3 \%$, mais dois, em $11,1 \%$, mais três e em $1,3 \%$, mais quatro. Os medicamentos prescritos com os antibacterianos foram basicamente analgésicos e antipiréticos, broncodilatadores, anti-histamínicos e solução nasal de cloreto de sódio. Dentreesses, os medicamentos mais prescritos foram a dipirona $(26,5 \%)$, salbutamol $(11,7 \%)$, paracetamol $(8,0 \%)$, neomicina tópica $(6,8 \%)$, solução nasal de cloreto de sódio $(4,8 \%)$ edexclorfeniramina (4,0\%). Medicamentos variados de diversas classes terapêuticas estiveram presentes em $38,2 \%$ das prescrições. A associação deantimicrobiano sistêmico com ou- tro antimicrobiano tópico foi utilizada nos casos das infecções de pele.

Os pediatras foram os principais prescritores de antimicrobianos (50,3\%), enquanto a especialidade médica que apresentou os piores re sultados de adequação, de uma forma geral, foi a dos clínicos (Tabela 4). Os generalistas apresentaram percentuais baixos nos itens indicação do antibacteriano para a HD registrada e duração do tratamento.

A Tabela 5 apresenta o percentual de adequação da escolha do antimicrobiano, dose, intervalo entre doses e duração do tratamento, de acordo com a HD. Observa-se que, em termos de adequação, os piores resultados são os do tratamento da doença pulmonar obstrutiva crônica (DPOC)/bronquite, feridas infectadas e celulite.

Tabela 3. Adequação dos aspectos posológicos, duração do tratamento e seleção do antimicrobiano a hipótese diagnóstica de acordo com protocolos da literatura.

\begin{tabular}{llcrrrr}
\hline & & $\begin{array}{c}\text { Número de } \\
\text { prescrições }\end{array}$ & AM X (\%) & BPG (\%) & SM T/TMP(\%) & ERT(\%) \\
\hline Dose & adulto & 69 & 100,0 & 100,0 & 76,5 & 100,0 \\
& pediatria & 73 & 87,9 & 100,0 & 88,9 & 100,0 \\
\multirow{2}{*}{ Intervalo } & adulto & 68 & 100,0 & 100,0 & 85,0 & 100,0 \\
\multirow{4}{*}{ Duração de tratamento } & pediatria & 106 & 98,3 & 100,0 & 100,0 & 85,7 \\
& adulto & 68 & 88,5 & 100,0 & 81,0 & 40,0 \\
Adequação do ATM à HD & pediatria & 95 & 90,1 & 100,0 & 100,0 & 100,0 \\
& adulto & 45 & 94,4 & 40,0 & 73,3 & 50,0 \\
& pediatria & 78 & 75,0 & 90,5 & 83,3 & 66,7 \\
\hline
\end{tabular}

Fonte: Secretaria M unicipal de Saúde de Belo H orizonte, 2002.

AM X- Amoxicilina; ERT- Eritromicina; BPB- Benzilpenicilina Benzatina; SM T/TRP-Sulfametoxazol+Trimetroprim

Tabela 4. Adequação da dosagem, intervalo entre doses, duração do tratamento e da seleção do atimicrobiano por especialidade médica do prescritor.

\begin{tabular}{lccccc}
\hline Especialidade do prescritor & $\begin{array}{c}\text { Adulto } \\
\text { N }(\%)\end{array}$ & $\begin{array}{c}\text { Pediatria } \\
\text { N }(\%)\end{array}$ & $\begin{array}{c}\text { Intervalo } \\
\text { entre doses } \\
\text { N }(\%)\end{array}$ & $\begin{array}{c}\text { Duração do } \\
\text { tratamento } \\
\text { N }(\%)\end{array}$ & $\begin{array}{c}\text { Antimicrobiano } \\
\text { selecionado } \\
\text { N (\%) }\end{array}$ \\
\hline Pediatra & - & $54(100,0)$ & $93(96,8)$ & $84(97,6)$ & $71(78,9)$ \\
Clínico & $35(100,0)$ & - & $40(95,0)$ & $40(95,0)$ & $24(62,5)$ \\
Generalista & $16(100,0)$ & $10(90,0)$ & $41(100,0)$ & $32(82,1)$ & $6(83,3)$ \\
Ginecologista & $4(100,0)$ & - & $9(100,0)$ & $8(100,0)$ & $28(78,6)$ \\
\hline
\end{tabular}

Fonte: Secretaria M unicipal de Saúde de Belo H orizonte, 2002. 
Tabela 5. Adequação do antimicrobiano, dose, intervalo entre doses e tempo de tratamento por hipótese diagnóstica registrada.

\begin{tabular}{lcccc}
\hline Hipótese diagnóstica & Antimicrobiano (\%) & Dose (\%) & $\begin{array}{c}\text { Intervalo entre } \\
\text { doses (\%) }\end{array}$ & $\begin{array}{c}\text { Tempo de } \\
\text { tratamento (\%) }\end{array}$ \\
\hline Tonsilite & 92,3 & 42,3 & 96,2 & 88,5 \\
OM A & 94,4 & 33,3 & 100,0 & 94,4 \\
ITU & 88,9 & 50,0 & 94,4 & 83,3 \\
Impetigo & 76,9 & 0,0 & 92,3 & 100,0 \\
DPOC/bronquite & 11,1 & 11,1 & 100,0 & 77,8 \\
IVAS & 60,0 & 30,0 & 100,0 & 80,0 \\
Infecções associadas & 81,8 & 27,3 & 90,9 & 72,7 \\
Sinusite/rinosinusite & 77,8 & 44,4 & 100,0 & 66,7 \\
Feridas infectadas & 22,2 & 77,8 & 100,0 & 88,9 \\
Celulite & 33,3 & 33,3 & 100,0 & 66,7 \\
Pneumonia & 100,0 & 100,0 & 100,0 & 100,0 \\
Asma & 0,0 & 0,0 & 100,0 & 100,0
\end{tabular}

Fonte: Secretaria M unicipal de Saúde de Belo H orizonte, 2002.

\section{Discussão}

A amostra foi constituída em sua maioria por crianças (59,9\%). A predominância do consumo deantimicrobianosnainfância tem sido demonstrada em vários estudos e justifica-se pelo perfil demorbidades característico dessa faixa etária ${ }^{1,2,17}$.

Verificou-se, em $23 \%$ dos prontuários, o registro de mais de uma prescrição de antimicrobiano nos seis meses em torno da consulta. Embora, em apenas $8,6 \%$ dos casos, a HD tenha sido a mesma, a freqüência de prescrição de antimicrobiano é importante para se avaliar a falência do tratamento e recorrência de infecções. Schindler et al. ${ }^{1}$, em um estudo na Alemanha, observaram que, em um período de dois anos, mais de $30 \%$ das crianças receberam dois ou mais antimicrobianos.

Entre as causas mais freqüentes de prescrição de antimicrobianos, encontram-se as IVAS, que foram responsáveis por $43 \%$ das receitas. Esta observação confirma dados da literatura em que as IVAS aparecem como principal motivo de uso de antimicrobianos ${ }^{6,7}$. Admite-se, contudo, que a etiologia dos processos infecciosos das vias aéreas superiores é em grande parte viral, tornando discutível a necessidade de antibioticoterapia no caso de diagnóstico inespecífico. Possivelmente, a dificuldade de se estabelecer a etiologia e a limitada disponibilidade de exames complementares rápidos ao nível ambulatorial influenciam o prescritor a optar pela antibioticoterapia. Entretanto, conforme enfatizado por Dosh et al. ${ }^{18}$, a alta freqüência da prescrição de antimicrobianos para infecções respiratórias agudas, inclusive as de origem viral, traz pouco ou nenhum benefício, mas acarreta custo significativo para 0 serviço de saúde e grande contribuição para a emergência e transmissão de bactérias resistentes. Rey et al. ${ }^{17}$ consideram que o mais prudenteé não se estabelecer um tratamento antibiótico, já que a maioria das IVAS é de etiologia viral. Vale ressaltar que, no presente estudo, considerou-se a IVAS, mesmo quando inespecífica, como passível de tratamento antibiótico, uma vez que não seincluiu a certificação do diagnóstico de doença bacteriana.

A otite média aguda (OMA) foi o segundo diagnóstico mais freqüente $(13,8 \%)$ juntamente com as infecções do trato urinário (ITU). Schindler et al. ${ }^{1}$ observaram ser esta a causa mais freqüente da prescrição de antimicrobianos para crianças de 0-6 anos na Alemanha. M c Ewen et al. ${ }^{19}$ ressaltam que, devido à alta incidência de OM A, a terapia antimicrobiana destequadro tem um alto potencial para o desencadeamento de resistência. As ITU são mais freqüentes em muIheres adultas e contribuíram com $13,8 \%$ dos casos. Entre as infecções de pele, destaca-se 0 impetigo, quefoi responsável por $10,8 \%$ das prescrições. Verificou-se ainda que, em cerca de $30 \%$ dos prontuários, a HD estava ausente. A ausência da HD foi observada também por Shindler et al. ${ }^{1}$, em $9 \%$ dos casos estudados entre crianças, na Alemanha. Esta ausência é altamente preocupante, pois o registro da HD no prontuário é a 
principal forma de se recuperar a história clinica do paciente e pode comprometer 0 atendimento por equipemultidisciplinar.

A amoxicilina foi o antimicrobiano mais prescrito. 0 perfil farmacológico da amoxicilina, um antimicrobiano de amplo espectro, de administração oral e boa tolerabilidade, faz com que este antibiótico seja de primeira escol ha para o tratamento de várias condições de atendimento na atenção primária. A benzilpenicilina benzatina, apesar de apresentar vários inconvenientes relacionados a sua forma farmacêutica e formulação, apareceno presente trabal ho como o segundo antimicrobiano mais prescrito. Possivelmente, seu baixo custo e a comodidade posológica (dose única) justifiquem esse achado. 0 sulfametoxazol+ trimetoprim é fármaco de escolha para o tratamento de ITU não complicada, sendo esta uma das suas principais indicações observadas nesse estudo. A eritromicina, um macrolídeo de primeira geração, tem indicações mais restritas, sendo observado um baixo percentual de prescrição desse antimicrobiano no presente estudo. Ressalta-se que o perfil de prescrição de antimicrobianos observado é determinado pela padronização local, o quejustifica a pequena freqüência verificada na prescrição de fármacos de segunda geração, não disponíveis no serviço.

Os resultados de adequação da seleção do antimicrobiano assemel ham-se aos encontrados por Rey et al. ${ }^{17}$ e Arnold et al.$^{20}$, que observaram índices de 28,4\% e27\% deinadequação em atenção primária, respectivamente. Contudo, devese considerar que esses estudos incluíram a avaliação do diagnóstico, a necessidade da prescrição ea sel eção do antimicrobiano. Vergeles-Blanca et al. ${ }^{4}$ encontraram escolha incorreta do antimicrobiano em $32 \%$ dos casos de pacientes que receberam alta de um serviço hospitalar de urgência na Espanha.

Os resultados encontrados por esses pesquisadores sugerem que a grande maioria dos diagnósticoséfeita apenas pelo exameclínico, estando, de modo geral, de acordo com as recomendações da literatura, não mostrando sobrecarga no pedido de exames. Colgan \& Power ${ }^{21}$ enfatizam que, apesar das dificuldades deseestabelecer a etiologia das infecções, éimportante que o diagnóstico seja baseado na história eno examefísico do paciente, utilizando-semeios diagnósticos laboratoriais nos casos em que forem essenciais para a definição do diagnóstico. A disponibilidade e a utilização das técnicas diagnósticas adequadas, nos casos em que se fizerem necessárias, podem contribuir para a utilização racional de antimicrobianos.
$\mathrm{Na}$ ausência de dados laboratoriais para confirmar a HD e o agente etiológico, a prescrição empírica deve ser baseada em guias e protocolos detratamento atualizados, em conformidadecom os padrões nosológicos de resistência locais. A auditoria sistemática torna-se, neste contexto, uma ferramenta importante que permite verificar a utilização dos guias terapêuticos e a adesão aos protocolos propostos, assim como estabelecer medidas corretivas, sefor o caso. 0 suprimento regular dos agentes indicados nestes guias é condição fundamental para adesão aos mesmos ${ }^{22}$. N as unidades públicas de saúde de Belo H orizonte, os protocolos são formatados como boletins de informação terapêutica (BIT) e são divulgadoserepassados aos médicos; entretanto, as auditorias sistemáticas não são realizadas. A adoção deauditorias erevisões de protocolos podecontribuir para a padronização das condutas, permitindo o uso mais racional dos antimicrobianos.

Em relação à prescrição, verificaram-se problemas relacionados à seleção do antimicrobiano paraa H D registradae, mais especificamente, problemas com a definição do tempo de tratamento. No primeiro caso, parece haver uma falha na divulgação e adesão aos BIT e/ou no processo de formação e atualização médica. A adoção de tratamentos em desacordo com as recomendações da literatura, em geral, leva a piores resultados quanto à evolução do processo e traz preocupação quanto à exposição desnecessária de pacientes a tratamentos que, em princípio, não são os mais adequados, podendo incidir em maiores custos individuais e coletivos. Diversos autores observaram ser este um dos problemas mais freqüentes com a prescrição de antimicrobianos ${ }^{2,9}$. M c Ewen et al..$^{19}$ observaram que, embora a amoxicilina seja considerada de primeira escolha para o tratamento da OM A, em apenas $31 \%$ dos casos este foi o antimicrobiano prescrito.

No que se refere ao tempo de tratamento, verifica-se uma variabilidade na prática médica quanto ao período de tratamento. Essa variabilidade foi observada também nos estudos de Fijn et al. ${ }^{9} \mathrm{eM}$ c Ewen et al. ${ }^{19}$. Isto possivelmentereflete a ten dência da literatura de se instituírem intervalos variáveis conforme a evolução clínica do quadro, o que pode influenciar os prescritores a se decidirem individual mente pelo intervalo considerado, a priori, como o mais adequado. Contudo, essa conduta deve ser utilizada com muita cautela, na medida em que pode ocasionar um tratamento por período inferior ao necessário e, neste caso, além da falha terapêutica, pode-se estar favorecendo o desenvolvimento de linha- 
gens resistentes de microorganismos. Por outro lado, o tratamento por tempo superestimado pode predispor 0 indivíduo a reações adversas e aumentar os gastos de recursos assistenciais com medicamentos.

A pediatria aparece, no presente estudo, como a especialidade com maior índice de prescrição de antimicrobiano, concentrando cerca de $50 \%$ dos prescritores. Essa especialidade apresentou ainda os mais altos índices de adequação das variáveis estudadas. Vale ressaltar, contudo, que houve uma grande perda de informação na faixa etária atendida pela especialidade, determinada pela falta de registro do peso do paciente.

O bservou-seque, em $82 \%$ dos casos, foi prescrito pelo menos mais um medicamento além do antimicrobiano, com média de 2,3 medicamentos por prescrição. 0 perfil de medicamentos prescritos parece compatível com o tratamento das doenças respiratórias, estando de acordo com a constatação de que as infecções respiratórias são as principais causas de atendimento. Sabendo tratar-se, em grandeparte, de pacientes pediátricos $(59,9 \%)$, este dado sugere uma exposição expressiva de crianças a medicamentos.

No presente estudo, pôde-se constatar a falta sistemática de registro de dados, entre os quais destacam-se data de nascimento, peso, HD, presença de co-morbidades e dados técnicos do medicamento, tais como apresentação e forma farmacêutica. Salienta-se, particularmente, a ausência dos referidos dados no caso de pacientes pediátricos, queconstituem cerca de $60 \%$ da amostra. A ausência do registro do peso comprometeu a análise de adequação de dose proposta neste trabal ho e deixou dúvidas quanto a se 0 dado não foi registrado ou se não foi feita a pesagem da criança. 0 peso é um parâmetro essencial para ajuste de dose na pediatria e para o acompanhamento do desenvolvimento infantil. A ausência dessa informação é particularmente importante por tratar-sede população proveniente, em grande parte, de vilas e favelas, onde, em geral, concentram-se os problemas relativos à desnutrição emortalidade infantil. A falta dessas informações prejudica a avaliação e o acompanhamento dos pacientes nas consultas subseqüentes. A incidência de elevados índices de ausência das informações deveser seriamenteavaliada, principalmente quando se considera que, nos diversos níveis de atenção, os profissionais envolvidos devem trabalhar conjuntamente em função do restabelecimento ou manutenção da saúde do paciente e prevenção de doenças. É importante destacar que não somente o médico, mas uma equipe multi- profissional, dependem dessas informações para realizarem suas funções de forma satisfatória.

Em relação à adequação do antimicrobiano, dose, intervalo entre doses e duração do quadro clínico relatado, observa-se que o tratamento da DPOC, da celulite e das feridas infectadas constitui problema principalmente quanto à escolha do antimicrobiano, com índices de adequação inferiores a $35 \%$. No que se refereà dose, osíndices de não-concordância com o preconizado são alarmantes, destacando-se que apenas para 0 tratamento da pneumonia as doses se mostram adequadas na totalidade. 0 intervalo entre doses foi o item com maior grau de adequação para todos os quadros. A duração do tratamento, além de grande variabilidade, mostrou discordâncias importantes com o preconizado na literatura para grande parte das morbidades relatadas. Considerando-se tais resultados, é importante ressaltar a necessidade de divulgação dos protocolos e a monitoração da adesão dos prescritores aos tratamentos propostos.

Finalmente, deve-se considerar que o principal fator para o uso racional do antimicrobiano é a presença da doença bacteriana. Este aspecto não foi objeto deste estudo, o que pode influenciar fortementeos resultados deadequação apresentados aqui, já que mais de $40 \%$ das HD registradas apontavam para IVAS e, segundo vários autores, estas podem ser, em grande parte, de origem viral. Estudos futuros podem contribuir para uma avaliação mais rigorosa da prescrição de antimicrobianos no serviço público de saúde de Belo Horizonte.

\section{Conclusão}

A literatura aponta vários fatores que contribuem para uma utilização não-racional dos antibióticos, dentre eles o desconhecimento da prevalência real das doenças infecciosas, as limitações enfrentadas pelo prescritor no estabelecimento do diagnóstico, as dificuldades na seleção do antimicrobiano mais apropriado, problemas na prescrição efatores econômicos que são influenciados pela grande disponibilidade e pela propaganda pouco controlada destes medicamentos ${ }^{3}$. A realização do presente estudo permitiu a observação de alguns desses fatores nas unidades de saúde da GERSA-CS. Entretais fatores, merecem destaque as prescrições empíricas de antimicrobianos, principalmenteparainfecções inespecíficas, as dificuldades de seleção da melhor opção terapêutica disponível eas deficiências na 
definição de dose, intervalo entre doses e tempo de tratamento, aspectos que podem comprometer todo o tratamento.

A análise das variáveis da prescrição por HD relatada aponta para a necessidade de revisão e divulgação dos protocolos, reforçando aspectos dos esquemas terapêuticos preconizados e enfatizando a alta prevalên cia das infecçãoes das vias aéreas superiores, da otite media aguda e das infecções do trato urinário em atenção primária.

Por meio deste estudo, pôde-se constatar a necessidade de interven ções no sentido de melhorar a qualidade das prescrições, da seleção do antimicrobiano e do registro das informações nos prontuários.

Estudos de utilização de antimicrobianos em atenção primária são ferramentas importantes para o diagnóstico das condições de utilização desses medicamentos, visando à instituição de políticas de saúde que restrinjam seu uso, como forma de prevenir a falência dos esquemas terapêuticos atuais.

\section{Referências}

1. Schindler C, Krappweis J, M orgenstern I, Kirch W. Prescriptions of systemic antibiotics for children in Germany aged between 0 and 6 years. Pharmacoepidemiol Drug Saf 2003; (12):113-120.

2. Las enfermedades infecciosas en atención primaria. Mejorar su manejo y utilizar adecuadamente los antimicrobianos [editorial]. Aten Primaria 1999; 24(10):553-555.

3. Wilson RPH, Hatcher J, Barton S, Walley T. The association of some practice characteristics with antibiotic prescribing. Pharmacoepidemiol Drug Saf 1999; (8):15-21.

4. Vergeles-Blanca JM, Aguillar JAF, Bermejo RH, Retamosa FE, Torres JAC, Buitrago F. Calidad y características de la prescripción de antibióticos en un servicio hospitalario de urgências. Rev Esp Salud Pública 1998; (72):111-118

5. Lirola MAG, Barrera JC, Garcia JMI, Asencio ARE. La calidad de la prescripción de antibacterianos en un distrito de atención primaria. Evolución 19941995. Aten Primaria 1997; (19):487-492.

6. Stratchounski LS, Andreeva IV, Hatchina SA, Galkin DV, Petrotchenkova NA, Demin AA, Kuzin VB, Kusnetsova ST, Likhatcheva RY, Nedogoda SV, Ortenberg EA, Belikov AS, Toropova IA. The inventory of antibiotics in Russian Home Medicine Cabinets. Clin Infect Dis 2003; (37):498-508.

7. Wenzel R, Edmond M. Managing antibiotic resistance. New Eng J M ed 2000; (343):1961-1963.

8. Marlière G, Ferraz M, Quirino dos Santos J. Consumo ambulatorial e sobras de antibióticos: entrevista em 6000 domicílios brasileiros. Ver Bras M ed 2000; (57):187-195.

9. Fijn R, Chow MC, Schuur PMH, De Jong-Van Den Berg LTW, Brouwers RBJ. Multicentre evaluation of prescribing concurrence with anti-infective guidelines: epidemiological assessment of indicators. Pharmacoepidemiol Drug Saf 2002; (11):361-372.

10. Lesar TS. Errors in the use of medication dosage equations. Arc Ped Adol M ed 1998; (152):340-344.

11. MCCaig LF, Hughes JM. Trends in antimicrobial drug prescribing among office-based physicians in the United States. JAM A 1995; (273):214-219.
12. Prefeitura M unicipal de Belo Horizonte. $\mathrm{BH}$ da gente - Conselhos Regionais Populares. Belo Horizonte: Prefeitura Municipal de Belo Horizonte; 2001.

13. World Health Organization. Anatomical Therapeutic Chemical - ATC-Classification index with Defined Daily Doses (DDDs). Norway: WHO; 2000.

14. Drug Information for health care professional - USPDI. Taunton, M assachusetts: Rand M CNally; 2002.

15. Brasil. Ministério da Saúde. M anual de condutas médicas: Programa de Saúde da Família. São Paulo: Ministério da Saúde; 2001.

16. Mandell GL, Bennett JE, Dolin R. Principles \& practice of infectious diseases. Taunton, M assachusetts: Rand M CN ally; 2002.

17. Rey CC, Ballesteros RA, M éndez MYS, Dominguez AO. Patrones de prescripción de antibióticos en atención primaria. Usamos racionalmente los antibióticos en pediatria? Aten Primaria 2000; (52):157-163.

18. Dosh SA, Hickner JM, M ainous AG, Ebell MH. Predictors of antibiotic prescribing for nonspecific upper respiratory infections, acute bronchitis, and acute sinusitis. J Fam Pract 2000; (49):407-414.

19. Mc Ewen LN, Farjo R, Foxman B. Antibiotic prescribing for otitis media: how well does it match published guidelines? Pharmacoepidemiol Drug Saf 2003: (12):213-219.

20. Arnold SR, Allen UD, Al-Zahrani M, Tan DHS, Wang EEL. Antibiotic prescribing by pediatricians for upper respiratory tract infection in children. Clin Infect Dis 1999; (29):312-317.

21. Colgan R, Powers JH. Appropriate antimicrobial prescribing: approaches that limit antibiotic resistance. Am Fam Phys 2001; (18):15.

22. Williams RJ, Heymann DL. Containment of antibiotic resistance. Science 1998; (279):1153-1155.

Artigo apresentado em 30/05/2006

Aprovado em 26/01/2007

Versão final apresentada em 13/04/2007 